\title{
Distinct DNA repair pathways involving RecA and nonhomologous end joining in Mycobacterium smegmatis
}

\author{
Malgorzata Korycka-Machala ${ }^{1}$, Anna Brzostek ${ }^{1}$, Sylwia Rozalska², Anna Rumijowska-Galewicz ${ }^{1}$, \\ Renata Dziedzic ${ }^{1}$, Richard Bowater ${ }^{3}$ \& Jaroslaw Dziadek ${ }^{1}$ \\ ${ }^{1}$ Centre of Medical Biology, Polish Academy of Sciences, Lodowa, Poland; ${ }^{2}$ Department of Industrial Microbiology \& Biotechnology, University of Lodz, \\ Banacha, Poland; and ${ }^{3}$ School of Biological Sciences, University of East Anglia, Norwich, UK
}

\begin{abstract}
Correspondence: Jaroslaw Dziadek, Centre of Medical Biology, Polish Academy of Sciences, 93-232 Lodz, Lodowa 106, Poland. Tel.: +4842 2723610; fax: +4842 2723630; e-mail: jdziadek@cbm.pan.pl
\end{abstract}

Received 10 January 2006; revised 11 February 2006; accepted 16 February 2006.

First published online 16 March 2006.

doi:10.1111/j.1574-6968.2006.00199.x

Editor: Roger Buxton

\section{Keywords}

Mycobacterium smegmatis; nonhomologous end joining; RecA; DNA ligase; DNA damage; mitomycin $C$.

\begin{abstract}
Mycobacterium smegmatis was used to study the relationship between DNA repair processes involving RecA and nonhomologous end joining (NHEJ). The effect of gene deletions in recA and/or in two genes involved in NHEJ ( $k u$ and $l i g D)$ was tested on the ability of bacteria to join breaks in plasmids transformed into them and in their response to chemicals that damage DNA. The results provide in vivo evidence that only NHEJ is required for the repair of noncompatible DNA ends. By contrast, the response of mycobacteria to mitomycin C preferentially involved a RecA-dependent pathway.
\end{abstract}

\section{Introduction}

Double-strand breaks (DSBs) are a specific type of DNA damage that may form during problems encountered during DNA metabolism (e.g. when replication forks meet obstacles or single-strand breaks) or due to the action of exogenous chemicals or radiation (Jackson, 2002; Lieber et al., 2003). DSBs sometimes arise during normal physiological processes, for example in $\mathrm{V}(\mathrm{D}) \mathrm{J}$ recombination of immunoglobulin genes, but they are also particularly potent in causing problems for cellular metabolism. All organisms have a range of cellular pathways that repair DSBs. The majority of repair of DSBs is performed by two pathways, homologous recombination (HR) and nonhomologous end joining (NHEJ).

In prokaryotes, it has been assumed that the main pathway that promotes repair of DSBs is HR, which uses RecA to facilitate the exchange of single strands of DNA. However, RecA has other distinct biochemical activities that are used in other cellular pathways in bacteria, most notably the SOS response (Lusetti \& Cox, 2002). Recent analysis of genome sequences identified potential prokaryotic homologues of two proteins known to be involved in NHEJ, namely Ku and an 'NHEJ-type' of DNA ligase (Aravind \& Koonin, 2001;
Doherty et al., 2001; Weller \& Doherty, 2001; Bowater \& Doherty, 2005; Hefferin \& Tomkinson, 2005). Mycobacteria are the organisms in which prokaryotic NHEJ has been described best. Biochemical analyses of recombinant versions of the proteins from Mycobacterium tuberculosis suggest that $\mathrm{MtKu}$ and $\mathrm{MtLigD}$ are able to form a functional NHEJ-processing system (Weller et al., 2002; Della et al., 2004). In support of this, deletion of $\operatorname{lig} D$ in both $M$. tuberculosis and Mycobacterium smegmatis generated cells that were defective in NHEJ (Gong et al., 2004, 2005). Use of the M. smegmatis system showed that NHEJ of blunt-end and complementary $5^{\prime}$-overhang DSBs involves several DNA end-remodelling activities and is highly mutagenic (Gong et al., 2005).

It is clear that many genes are involved in the response to DNA damaging agents, as demonstrated for the effect of mitomycin C (MMC) on Escherichia coli (Khil \& CameriniOtero, 2002). Analysis of the effects of MMC on different mycobacteria has identified varying effects, with not all being related to expression of recA (Papavinasasundaram et al., 2001; Davis et al., 2002; Rand et al., 2003). Moreover, studies in yeast and mammalian cells identified the involvement of different pathways in the repair of interstrand crosslinks (ICLs), with NHEJ being important during some 
parts of the cell cycle (De Silva et al., 2000; McHugh et al., 2000). The potential for interactions between different DNA repair pathways leads to questions about the extent of overlap and cross-talk between them. In this study, we use M. smegmatis to examine the relationship between pathways involving RecA or NHEJ, which are known to be able to repair similar types of damage.

\section{Materials and methods}

\section{Bacterial strains and growth conditions}

All strains used in this study were based on Mycobacterium smegmatis $\mathrm{mc}^{2} 155$ (Snapper et al., 1990) and were cultured in Middlebrook 7H9 broth supplemented with albumindextrose-sodium chloride or NB broth: nutrient broth (Difco, Kansas city, MO), $8.0 \mathrm{~g} \mathrm{~L}^{-1}$; glucose, $10.0 \mathrm{~g} \mathrm{~L}^{-1}$; supplemented with Tween 80, 0.2\% (pH 6.0-6.2) and kanamycin, $25 \mu \mathrm{g} \mathrm{mL}^{-1}$ when required. Mycobacterial transformants were selected on Middlebrook 7H10 enriched with albumin-dextrose-sodium chloride containing either kanamycin $\left(25 \mu \mathrm{g} \mathrm{mL}^{-1}\right)$ or hygromycin $\left(10 \mu \mathrm{g} \mathrm{mL}^{-1}\right)$.

\section{Gene cloning strategies}

Standard molecular biology protocols were used for all cloning protocols (Sambrook \& Russell, 2001). All PCR products were obtained using thermostable ExTaq polymerase (Takara, Japan) and cloned initially into a TA vector (pGEM-Teasy, Promega, Madison, WI), and then released by digestion with appropriate restriction enzymes before cloning into the final vectors. To facilitate subcloning into expression vectors, restriction enzyme recognition sites were incorporated in the sequence of the primers. The plasmids used in this work are listed in Table 1.

\section{Targeted gene replacement}

To perform unmarked deletions in the ligD (MSMEG5550), $k u$ (MSMEG5560) and recA (MSMEG2725) genes of $M$. smegmatis, suicidal recombination delivery vectors were constructed. Each recombination vector contained the $5^{\prime}$ end of the appropriate gene ( $56 \mathrm{bp}-l i g D ; 53 \mathrm{bp}-k u$; $51 \mathrm{bp}-$ rec $A$ ) with upstream regions connected to the $3^{\prime}$ end of the gene (894bp-ligD; $456 \mathrm{bp}-k u$; $539 \mathrm{bp}-\mathrm{rec} A$ ) with downstream regions. The $5^{\prime}$ and $3^{\prime}$ fragments of the genes in the resulting vectors were ligated out of frame, resulting in expression of nonfunctional proteins. The various fragments of each gene were amplified using primers listed in Table 2 as follows:

For ligD: $5^{\prime}$-end and upstream flanking sequence: DGR1+D-GR2; $3^{\prime}$-end and downstream flanking sequence: D-GR3+D-GR4.

Table 1. Plasmids used in this study

\begin{tabular}{|c|c|c|}
\hline Plasmid & Description & Source \\
\hline \multicolumn{3}{|c|}{ Cloning vectors } \\
\hline pGemTEasy & T/A cloning & Promega \\
\hline PMV306 & Mycobacterial integrating vector, $\mathrm{Kan}^{\mathrm{R}}$ & $\begin{array}{l}\text { Med-Immune Inc., } \\
\text { Gaithersburg, MD. }\end{array}$ \\
\hline p2NIL & Recombination vector, nonreplicating in mycobacteria, $\operatorname{Kan}^{R}$ & Parish \& Stoker (2000) \\
\hline pGoal17 & The source of Pacl cassette, $\mathrm{Amp}^{\mathrm{R}}$ & Parish \& Stoker (2000) \\
\hline pJam2 & Shuttle vector carrying inducible $\mathrm{P}_{a m i}$ promoter, $\mathrm{Kan}^{\mathrm{R}}$ & Triccas et al. (1998) \\
\hline pMV206 & Mycobacterial Escherichia coli shuttle vector, $\mathrm{Kan}^{\mathrm{R}}$ & Med-Immune Inc. \\
\hline \multicolumn{3}{|c|}{ Vectors used for gene replacement } \\
\hline pMK100 & Ku BamHI-Hindlll fragment including $5^{\prime}$ end and its upstream region (1053 bp) in p2NIL, Kan ${ }^{R}$ & This study \\
\hline pMK102 & Ku Pstl-HindIII fragment including $3^{\prime}$ end and its downstream region (1317 bp) in pMK100, $\operatorname{Kan}^{R}$ & This study \\
\hline pMK103 & pMK102 with Pacl cassette from pGoal17, Kan $^{R}$ & This study \\
\hline pMK108 & ligD HindllI-BamHI fragment including $5^{\prime}$ end and its upstream region (1973 bp) in p2NIL, Kan $^{\mathrm{R}}$ & This study \\
\hline pMK110 & ligD BamHI-Kpnl fragment including $3^{\prime}$ end and its downstream region (1770 bp) in pMK108, $\operatorname{Kan}^{R}$ & This study \\
\hline pMK111 & pMK110 with Pacl cassette from pGoal17, Kan R & This study \\
\hline pMK120 & recA Pstl-Hindlll fragment including $5^{\prime}$ end and its upstream region (1305 bp) in p2NIL, Kan $^{R}$ & This study \\
\hline pMK121 & recA Kpnl-Hindlll fragment including $3^{\prime}$ end and its downstream region (1366 bp) in pMK120, $\operatorname{Kan}^{R}$ & This study \\
\hline pMK122 & pMK121 with Pacl cassette from pGoal17, KanR & This study \\
\hline \multicolumn{3}{|c|}{ Over-production vectors } \\
\hline pMK112 & ku under $\mathrm{P}_{a m i}$ promoter in pJam2, $\operatorname{Kan}^{\mathrm{R}}$ & This study \\
\hline pMK113 & ligD under $\mathrm{P}_{a m i}$ promoter in pJam2, $\mathrm{Kan}^{\mathrm{R}}$ & This study \\
\hline pMK116 & $k u$ in $p M V 306, \operatorname{Kan}^{R}$ & This study \\
\hline pMK117 & ligD in $p M V 306, \operatorname{Kan}^{\mathrm{R}}$ & This study \\
\hline \multicolumn{3}{|c|}{ Recircularization assay vectors } \\
\hline pKSR11 & pMV206 carrying gfp in BamHI-Pstl sites, Kan $^{\mathrm{R}}$ & M. Rajagopalan (unpublished) \\
\hline pMV206-hyg & pMV206 carrying $\mathrm{Hyg}^{R}$ gene, $\mathrm{Kan}^{R}, \mathrm{Hyg}^{\mathrm{R}}$ & This study \\
\hline
\end{tabular}


Table 2. Primer sequences used for PCR amplification

\begin{tabular}{|c|c|c|}
\hline Amplified region & Primer name & Primer sequence \\
\hline \multicolumn{3}{|c|}{ Primers used to amplify DNA for targeted gene replacement } \\
\hline ligD 5' flanking region - sense & D-GR1 & $5^{\prime} c c c a a g c t t c g a t c c g t g g g g c g t g g t g 3^{\prime}$ \\
\hline ligD 5' flanking region - reverse & D-GR2 & $5^{\prime}$ cgggatccggattcgtcagg cgaacccgc $3^{\prime}$ \\
\hline ligD 3' flanking region - sense & D-GR3 & $5^{\prime}$ cgggatccgccaccgagggttccgtcgcg3' \\
\hline ligD $3^{\prime}$ flanking region - reverse & D-GR4 & $5^{\prime}$ gggtacctcgtcaccggcgccagcagc3' \\
\hline ku $5^{\prime}$ flanking region - sense & KuGR1 & $5^{\prime}$ сccaagcttctgtggeccgacgagatcc $3^{\prime}$ \\
\hline ku $5^{\prime}$ flanking region - reverse & KuGR2 & $5^{\prime}$ cgggatcccgccttgcggcggatcctcg3' \\
\hline ku $3^{\prime}$ flanking region - sense & KuGR3 & 5'aactgcaggcgatgacgtcgggcactgg $3^{\prime}$ \\
\hline ku $3^{\prime}$ flanking region - reverse & KuGR4 & $5^{\prime} c c c a a g c t t a c c g g c a c g t t c a c c a g g c c 3^{\prime}$ \\
\hline recA $5^{\prime}$ flanking region - sense & RecA-GR1 & 5'aactgcaggg $g$ cagggttcaccgatcgtg $3^{\prime}$ \\
\hline recA $5^{\prime}$ flanking region - reverse & RecA-GR2 & $5^{\prime} c c c a a g c t t g g c c a t c g c c a g t t c g a g g g c 3$ \\
\hline recA $3^{\prime}$ flanking region - sense & RecA-GR3 & $5^{\prime}$ cccaagcttgcctgatgagccaggcgctgc3 \\
\hline recA $3^{\prime}$ flanking region - reverse & RecA-GR4 & $5^{\prime}$ ggggtacctcgagatggtgcggcaaggc $3^{\prime}$ \\
\hline \multicolumn{3}{|c|}{ Primers used to clone genes for complementation experiments } \\
\hline ligD gene & MsD-s & $5^{\prime}$ cgggatccgtggcgaggcatccttgggg $3^{\prime}$ \\
\hline ligD gene & MsD-r & $5^{\prime}$ gctctagactattcccacacaacctcatcgg $3^{\prime}$ \\
\hline ku gene & MsKu-s & $5^{\prime}$ cggatccatgaaccgtgcggtacgcc3' \\
\hline ku gene & MsKu-r & $5^{\prime}$ gctctagactacgacttcttcgcagctgc $3^{\prime}$ \\
\hline
\end{tabular}

For the primers used to clone genes for complementation, underlined regions represent additional sequences, which include restriction sites used during cloning steps (BamHI, GGATCC; Xbal, TCTAGA).

For $k u$ : $5^{\prime}$-end and upstream flanking sequence: KuGR1+ KuGR2; $3^{\prime}$-end and downstream flanking sequence: KuGR3+ KuGR4.

For recA: $5^{\prime}$-end and upstream flanking sequence: RecAGR1+RecA-GR2; 3 '-end and downstream flanking sequence: RecA-GR3+RecA-GR4.

\section{Construction of complementation plasmids}

Two M. smegmatis genes (ligD and $k u$ ) were PCR amplified (using primers $[\mathrm{MsD}-\mathrm{s}+\mathrm{MsD}-\mathrm{r}]$ for $\operatorname{lig} \mathrm{D}$ and [MsKu$s+\mathrm{MsKu}-\mathrm{r}$ ] for $k u$ ) and cloned into BamHI-XbaI sites of pJam2 vector downstream from the $\mathrm{P}_{a m i}$ promoter (Table 2). Next, ligD and $k u$ genes with $\mathrm{P}_{a m i}$ promoter were excised from these vectors with HindIII and $\mathrm{XbaI}$ and cloned into the integration vector pMV306, generating pMK116 and pMK117 for $k u$ and $l i g D$, respectively.

\section{Disruption of $k u, l i g D$ and recA genes}

The protocol of Parish \& Stoker (2000) was used to disrupt the investigated genes at their native loci on the chromosome. The plasmid DNAs (pMK103, pMK111, pMK122) were treated with $\mathrm{NaOH}(0.2 \mathrm{mM})$ and integrated into the M. smegmatis $\mathrm{mc}^{2} 155$ chromosome by HR. The resulting single crossover recombinant (SCO) mutant colonies were blue, $\operatorname{Kan}^{\mathrm{R}}$ and sensitive to sucrose. The site of recombination was confirmed by PCR and Southern hybridization. The SCO strains were further processed to select for doublecrossover (DCO) mutants that were white, $\mathrm{Kan}^{\mathrm{S}}$ and resistant to sucrose $(2 \%)$. As required, further recombination events were used to generate double DCO (dDCO) and triple DCO (tDCO) strains. Analyses by PCR and Southern hybridization were used to distinguish between the wild type and each mutant DCO. Probes to hybridize to each gene were generated by PCR, with labelling by a nonradioactive primer extension system (DIG-labelling system, Amersham, Sweden) as follows: $m s l i g D=\operatorname{ligDs}$ and ligDr as primers and pMK110 as a template; $m s k u=k u-s, k u-r$ primers and pMK102 as a template; $m s r e c A=$ recA-s, recA-r primers and pMK121 as a template.

\section{Growth in the presence of DNA-damaging agents}

Experiments were performed with $\mathrm{MMC}$ and cis-platinum (cis-DDP), chemicals that are known to damage DNA.

Analysis of the effects on growth were performed as follows: $\mathrm{NB}$ medium $(50 \mathrm{~mL})$ containing $25 \mathrm{ng} \mathrm{mL}^{-1}$ of MMC was inoculated with exponentially growing cultures of wild-type and mutant strains to $\mathrm{OD}_{600 \mathrm{~nm}}=0.1$ and incubated for $4 \mathrm{~h}$ on a shaker at $37^{\circ} \mathrm{C}$. Then the cells were harvested by centrifugation, washed twice with MMC-free medium, suspended in $50 \mathrm{~mL}$ of a fresh $\mathrm{NB}$ broth and the cultures were grown for a further $45 \mathrm{~h}$ on a shaker at $37^{\circ} \mathrm{C}$. To determine the number of dividing cells in each culture, samples were collected and plated every 3 or $6 \mathrm{~h}$. An additional 1-3 mL samples were prepared as described previously (Dziadek et al., 2002) and analysed by a confocal imaging system (Pascal Zeiss Axiovert 200M Microscope, with a Plan Neofluor $\times 63$ oil immersion objective, Zeiss, Germany). Cell length was determined using the Zeiss LSM imaging software, with at least 50 individual cells being measured at each time point. 
Analyses of the effects on viability were performed as follows: actively growing cultures $\left(\mathrm{OD}_{600 \mathrm{~nm}}=0.6-0.8\right)$ were diluted to $\mathrm{OD}_{600 \mathrm{~nm}}=0.1$ and incubated with various concentrations of $\operatorname{MMC}\left(0,50,150 \mathrm{ng} \mathrm{mL}^{-1}\right)$ or cis-DDP $(0$ and $100 \mu \mathrm{M}$ ) for $4 \mathrm{~h}$. To determine the number of viable cells in each culture, the cells were washed as above, plated on NB plates and grown at $37^{\circ} \mathrm{C}$ for $72-96 \mathrm{~h}$.

\section{Transformation with linearized plasmids}

Plasmid DNA of Mycobacterium-Escherichia coli shuttle vector (pKSR11 or pMV206-hyg) was digested with BamHI or EcoRI and EcoRV enzymes, purified from an agarose gel and electroporated into $M$. smegmatis wild-type and mutant competent cells. The transformed cells were plated on 7H10-OADC plates with appropriate antibiotic. The quality of electroporated cells was verified with supercoiled DNA of the same vector. The plasmid DNA of transformants was recovered as described previously (Madiraju et al., 2000) and analysed by digestion with restriction enzymes and sequencing.

\section{Results}

\section{Disruption of Mycobacterium smegmatis ku, ligD and recA genes}

To allow evaluation of bacterial NHEJ and its interaction with other DNA repair processes, we constructed Mycobacterium smegmatis strains defective in production of proteins that are central to NHEJ (LigD and/or Ku) and HR (RecA).

The two-step recombination protocol (Parish \& Stoker, 2000) was used to generate unmarked deletions of all three genes within the $M$. smegmatis chromosome. The resultant mutants were verified by PCR and Southern hybridization (Fig. 1). The generation of these strains shows that $k u$, ligD and recA are not essential genes in $M$. smegmatis, in agreement with previous observations (Frischkorn et al., 1998; Gong et al., 2005). Furthermore, as it was possible to delete simultaneously all genes on the chromosome $(\Delta l i g D-\Delta k u-\Delta r e c A)$, NHEJ- and recA-dependent processes are not required when $M$. smegmatis grows in rich media. In such media and in the absence of DNA-damaging agents, there was no noticeable difference in the growth rates of the wild-type cells or those mutated for all three genes studied here (see Fig. 3a).

\section{NHEJ but not RecA is essential for re-circularization of incompatible ends in Mycobacterium smegmatis}

As plasmid DNA carrying ori-Al5000 is propagated in mycobacteria in a circular form, the linear form taken up during transformation must be ligated in vivo by cellular enzymes before replication proceeds. Use of linearized plasmids with selection markers means that only those cells containing re-circularized plasmids will be viable.

Plasmid DNA of the Escherichia coli-M. smegmatis shuttle vector pKSR11 was digested with restriction enzymes in order to produce ends that were compatible $(B a m \mathrm{HI})$ or incompatible (EcoRI in combination with EcoRV). After agarose gel purification, the DNA was transformed by electroporation into various strains of $M$. smegmatis (wildtype, $\Delta \operatorname{rec} A, \Delta l i g D, \Delta k u, \Delta l i g D-\Delta k u)$. The efficiency of transformation was calculated per $1 \mu \mathrm{g}$ of DNA and normalized by the number of transformants obtained with supercoiled, control DNA. In all experiments (Fig. 2), the efficiency of transformation with plasmid digested with $(E c o R I+E c o R V)$ was lower than that obtained with plasmid digested with $\mathrm{Bam} \mathrm{HI}$, in accordance with expectation that it is more difficult for the cell to process incompatible ends.

The efficiency of transformation for the $\delta$ recA strain and the control wild-type strain was very similar (Fig. 2). By contrast, $M$. smegmatis strains with deletions in the NHEJ genes $(\Delta l i g \mathrm{D}, \Delta k u$ and $\Delta k u-\Delta l i g \mathrm{D})$ were transformed with 83-96\% lower efficiency for BamHI-digested plasmid. For strains lacking functional NHEJ, it was generally not possible to obtain transformants with plasmid digested with $($ EcoRI+EcoRV).

Two additional control strains were prepared that allowed conditional complementation of the ligD and $k u$ deletions with additional copies of the relevant wild-type gene. The ligD and $k u$ under control of $\mathrm{P}_{a m i}$ were introduced into the attB site with integration plasmids pMK116 and pMK117. The strains were transformed with linearized-plasmid [pMV206-Hyg digested with BamHI and (EcoRI+EcoRV)], as described above. In all experiments, complementation of the mutant strains with the appropriate deleted gene returned the efficiency of transformation to the level of the wild-type strain (Fig. 2).

Thus, the presence of NHEJ proteins increased the efficiency of transformation by BamHI linearized plasmids and allowed the self-ligation of plasmids linearized by $E c o$ RI $+E c o$ RV. On the other hand, the presence of RecA is likely to be not significant for self-ligation of linearized plasmid DNA.

\section{An intact recA gene, but not ligD and $k u$, is essential to repair DNA damage induced by MMC}

Mitomycin C is a DNA-damaging agent, which induces mainly interstrand DNA cross-links, although processing of the damage is also likely to lead to the formation of DSBs (Dronkert \& Kanaar, 2001; Khil \& Camerini-Otero, 2002; Niedernhofer et al., 2004). Importantly, NHEJ is used to 
Fig. 1. Replacement of ligD, $k u$ and recA genes of Mycobacterium smegmatis with mutated genes. The chromosomal localization of each gene is represented by a grey arrow. Relevant restriction enzyme sites and the sizes of fragments obtained with the wild-type and deleted genes are denoted. A $1 \mathrm{~kb}$ ladder acted as a marker for each gel. (a) DNA was digested with Sacl and Clal. (a1) Southern analysis of genomic DNA isolated from wildtype M. smegmatis (wt) and recombinants: ligD $\Delta$ ligD [M. smegmatis ligD $\Delta$ ligD obtained by single crossover (SCO) recombination of the wild-type strain with plasmid DNA pMK111]; ligD (M. smegmatis ligD obtained from M. smegmatis ligD $\Delta$ ligD); $\Delta$ ligD (two constructs of $M$. smegmatis $\Delta /$ ligD). (a2) Southern analysis of genomic DNA isolated from wild-type M. smegmatis (wt) and recombinants: ligD $\Delta$ ligD $\Delta$ ku (M. smegmatis ligD $\Delta$ lig $D \Delta k u$ obtained by SCO recombination of the $M$. smegmatis $\Delta k u$ with plasmid DNA pMK111); $\Delta$ ligD $\Delta$ ku (M. smegmatis $\Delta l i g D \Delta k u)$. The DNA was identified by hybridization to a ligD-probe. The expected hybridization bands for the wild-type and mutated genes (2688 and 1307 bp, respectively) are indicated by arrows. (b) DNA was digested with Pvull. Southern analysis of genomic DNA isolated from wild-type $M$. smegmatis (wt) and recombinants: two constructs of ku$\Delta \mathrm{ku}$ (M. smegmatis kuAku obtained by SCO recombination of the wild-type strain with plasmid pMK103); ku (M. smegmatis ku obtained from M. smegmatis $k u \Delta k u)$; three constructs of $\Delta \mathrm{ku}(M$. smegmatis $\Delta k u)$. The DNA was identified by hybridization to a ku-probe. The expected hybridization bands for the wildtype and mutated genes (1264 and 777 bp, respectively) are indicated by arrows. (c) DNA was digested with Smal. Southern analysis of genomic DNA isolated from wild-type $M$. smegmatis (wt) and recombinants: recA $\Delta$ recA ( $M$. smegmatis recA $\triangle$ recA obtained by SCO recombination of the wild-type strain with plasmid pMK122); recA $\Delta$ recA $\Delta$ ligD $\Delta$ ku (M. smegmatis recA $\Delta$ recA $\Delta$ lig $D \Delta k u$ obtained by SCO recombination of the $M$. smegmatis $\Delta$ ligD $\Delta k u$ with plasmid pMK122); recA (M. smegmatis recA obtained from $M$. smegmatis recA $\Delta r e c A)$; recA $\Delta \operatorname{lig} D \Delta \mathrm{ku}(M$. smegmatis re$c A \Delta l i g \mathrm{D} \Delta k u$ obtained from $M$. smegmatis recA $\Delta$ recA $\Delta$ ligD $\Delta k u$ ); $\Delta$ recA ( $M$. smegmatis $\Delta r e c A)$; two constructs of $\Delta$ recA $\Delta$ ligD $\Delta$ ku $(M$. smegmatis $\Delta$ lig D $\Delta k u \Delta r e c A)$. The DNA was identified by hybridization to a $\Delta$ recA-probe. The expected hybridization bands for the wild-type and mutated genes (1360 and $858 \mathrm{bp}$, respectively) are indicated by arrows.
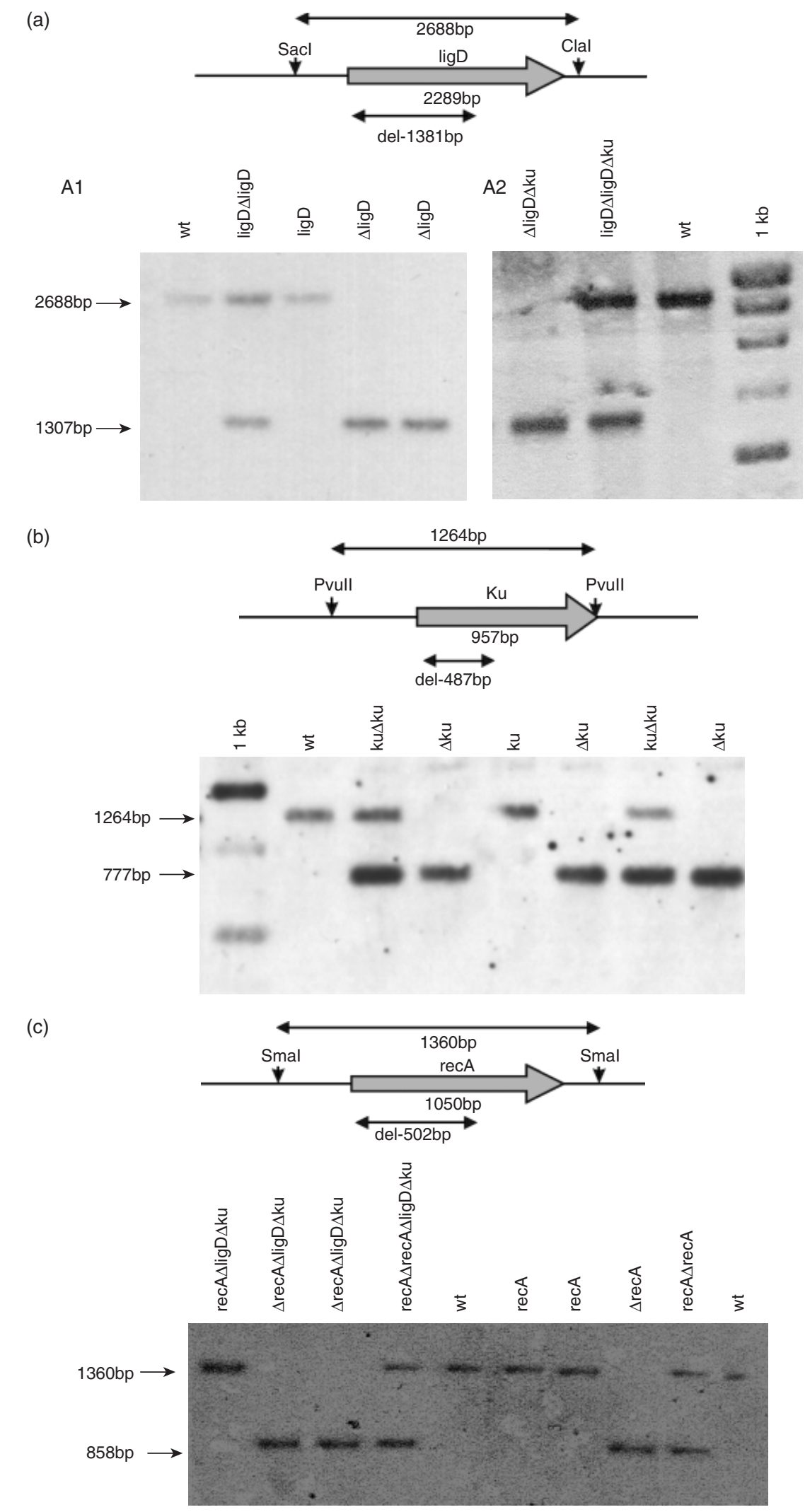


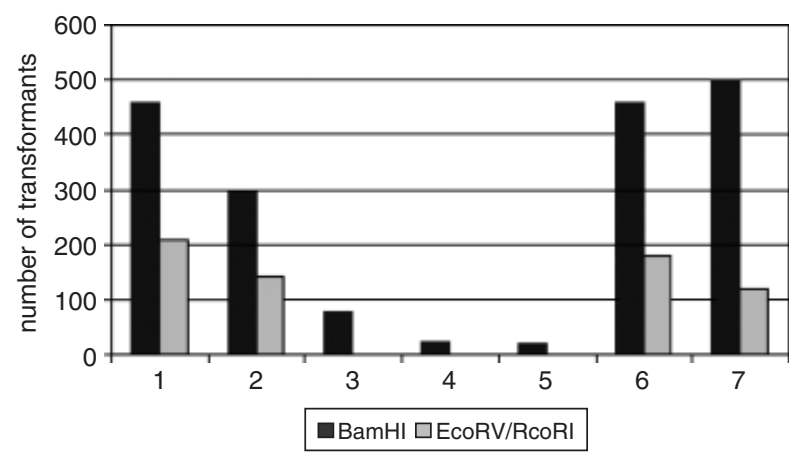

Fig. 2. Double-strand breaks in plasmids are repaired mainly by nonhomologous end joining. The efficiency of transformation with $0.5 \mu \mathrm{g}$ of linear plasmid DNA containing BamHI cohesive ends (black bar) or EcoRI/ EcoRV incompatible ends (grey bar) was measured. All experiments were performed in strains derived from Mycobacterium smegmatis $\mathrm{mc}^{2} 155$ as follows (x-axis): 1, wild type; 2, $\operatorname{rec} A ; 3, \Delta l i g D ; 4, \Delta k u ; 5, \Delta l i g D \Delta k u ; 6$, $\Delta$ ligD-PamiligD; 7, $\Delta k u-\mathrm{P}_{a m i k}$. Each transformation experiment was repeated three to five times with freshly prepared DNA and competent cells, with the representative result being presented in the figure. The $y$-axis represents the number of transformants obtained, calculated for $1 \mu \mathrm{g}$ of linear DNA.

repair damage induced by MMC in yeast and mammalian cells, albeit in a cell cycle-dependent manner (De Silva et al., 2000; McHugh et al., 2000). In the light of these previous observations, we wondered if NHEJ may play any role in the response of $M$. smegmatis to damage induced by MMC.

All strains constructed in this study were tested for their ability to grow with and without exposure to MMC. In the absence of DNA-damaging agents, the growth rates of the wild-type cells and those mutated for all three genes studied here were similar (Fig. 3a). Incubation of M. smegmatis cells with MMC decreased dramatically the viability of the $r e c A$ deletion strains (M. smegmatis $\Delta r e c A ; \Delta r e c A-\Delta l i g D-\Delta k u$ ) in comparison with wild-type and NHEJ-defective strains (Fig. 3b). NHEJ-defective and wild-type strains incubated with MMC had the same viability for the first $6 \mathrm{~h}$ after MMC treatment, but during further incubation wild-type cells grew faster than the NHEJ-defective mutants (see 9-30 h time points in Fig. 3b). No significant differences were observed in the number of viable cells for the $\Delta$ recA mutant and triple-mutant $(\Delta r e c A-\Delta l i g D-\Delta k u)$. This data suggests that the repair of DNA damaged with MMC is coordinated mainly by $r e c A$-dependent processes, with NHEJ playing a relatively minor role in such genome repair.

The observed increase in the number of RecA-defective cells after exposure to MMC could be due to the repair of DNA by RecA/NHEJ independent pathway(s) or could be due to a small population of cells that are undamaged by the MMC. To differentiate between these possibilities we increased the concentration of MMC and analysed the viability of the cells (data not shown). The highest concentration
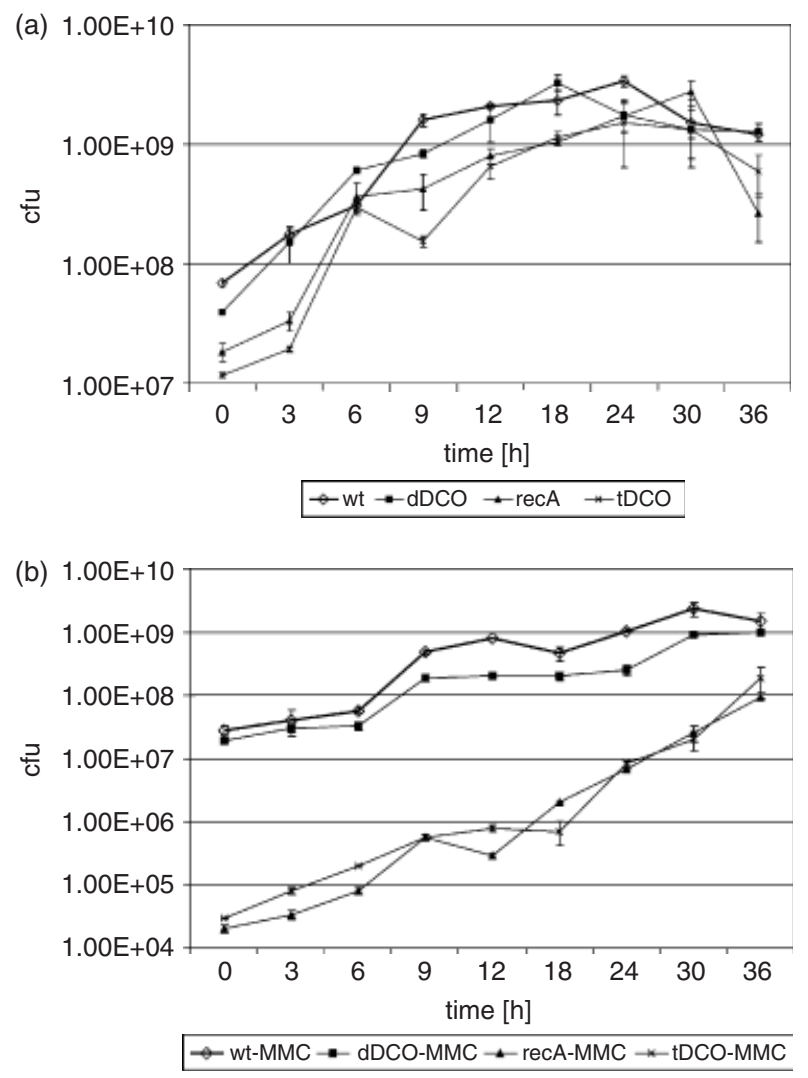

Fig. 3. Growth analysis of Mycobacterium smegmatis wild-type and RecA/nonhomologous end joining (NHEJ)-defective strains exposed (b) or not (a) to mitomycin C (MMC). The exponentially growing cultures of wild-type and mutant strains were diluted to $O D_{600 \mathrm{~nm}}=0.1$. A half of each diluted culture was supplemented with $25 \mathrm{ng} \mathrm{mL}^{-1}$ of $\mathrm{MMC}$ and incubated for $4 \mathrm{~h}$. The remaining half of each culture was incubated without MMC for the same period of time. Next, cells were harvested and suspended in the fresh MMC-free medium and incubated for $36 \mathrm{~h}$. (a) represents $36 \mathrm{~h}$ incubation time of cells that were not exposed to MMC. (b) represents $36 \mathrm{~h}$ incubation time of cells that were previously exposed to MMC. Zero (0) on the $x$-axis indicates time when medium of each culture [containing MMC - (b) or not (a)] was replaced with fresh MMC-free medium. The numbers of viable cells were determined by counting the number of colony forming units (cfu). Strain references are as follows: a - M. smegmatis wild type (wt); $M$. smegmatis $\Delta$ ligD $\Delta \mathrm{ku}$ (dDCO); M. smegmatis $\Delta$ recA (recA-); $M$. smegmatis $\Delta$ recAligD $\Delta k u$ (tDCO); $b-M$. smegmatis wild type treated with MMC, (wt-MMC); $M$. smegmatis $\Delta$ ligD $\Delta$ ku treated with $\mathrm{MMC}(\mathrm{dDCO}-\mathrm{MMC}) ; M$. smegmatis $\Delta$ recA treated with $\mathrm{MMC}(\mathrm{rec} A-\mathrm{MMC}) ; M$. smegmatis $\Delta$ recAligD $\Delta \mathrm{ku}$ treated with MMC (tDCO-MMC). The standard deviation was calculated from four independent experiments.

of MMC was lethal for all $\triangle r e c A$ mutants, suggesting that a RecA-dependent mechanism is essential for the repair of DNA damaged with MMC. Treatment with another mutagen, cis-DDP, produced similar observations. Cis-DDP at $500 \mu \mathrm{M}$ did not significantly decrease the viability of the wild-type strain or the $\Delta l i g D-\Delta k u$ mutant, but the viability of $\Delta \operatorname{rec} A$ strains decreased by 6-logs (data not shown). 
Table 3. Filamentation of cells resulting from inhibition of cell division

\begin{tabular}{|c|c|c|c|c|c|c|c|c|c|c|c|c|}
\hline \multirow[b]{4}{*}{ Strain } & \multicolumn{12}{|l|}{ Time (h) } \\
\hline & \multicolumn{3}{|l|}{0} & \multicolumn{3}{|l|}{12} & \multicolumn{3}{|l|}{24} & \multicolumn{3}{|l|}{45} \\
\hline & \multicolumn{3}{|c|}{ Cells length } & \multicolumn{3}{|c|}{ Cells length } & \multicolumn{3}{|c|}{ Cells length } & \multicolumn{3}{|c|}{ Cells length } \\
\hline & $\begin{array}{l}\text { Average } \\
\text { size }\end{array}$ & $\geq 8 \mu \mathrm{m}$ & $\geq 10 \mu \mathrm{m}$ & $\begin{array}{l}\text { Average } \\
\text { size }\end{array}$ & $\geq 8 \mu \mathrm{m}$ & $\geq 10 \mu \mathrm{m}$ & $\begin{array}{l}\text { Average } \\
\text { size }\end{array}$ & $\geq 8 \mu \mathrm{m}$ & $\geq 10 \mu \mathrm{m}$ & $\begin{array}{l}\text { Average } \\
\text { size }\end{array}$ & $\geq 8 \mu \mathrm{m}$ & $\geq 10 \mu \mathrm{m}$ \\
\hline mc2 & 4.402 & $1(2 \%)$ & $1(2 \%)$ & 3.967 & 0 & 0 & 2.984 & 0 & 0 & 2.893 & 0 & 0 \\
\hline Mc2-MMC & 5.966 & $7(14 \%)$ & $1(2 \%)$ & 4.359 & $2(4 \%)$ & $1(2 \%)$ & 3.075 & $3(6 \%)$ & $1(2 \%)$ & 3.3 & $2(4 \%)$ & $2(4 \%)$ \\
\hline $\mathrm{dDCO}$ & 4.303 & 0 & 0 & 3.823 & 0 & 0 & 2.559 & $1(2 \%)$ & $1(2 \%)$ & 2.443 & 0 & 0 \\
\hline dDCO-MMC & 6.748 & $13(26 \%)$ & $7(14 \%)$ & 5.403 & $7(14 \%)$ & $2(4 \%)$ & 3.578 & $1(2 \%)$ & $1(2 \%)$ & 3.606 & $2(4 \%)$ & $2(4 \%)$ \\
\hline RecA & 4.561 & $1(2 \%)$ & 0 & 4.197 & $1(2 \%)$ & 0 & 3.716 & 0 & 0 & 3.51 & 0 & 0 \\
\hline RecA-MMC & 5.975 & $5(10 \%)$ & $1(2 \%)$ & 8.139 & $16(32 \%)$ & $10(20 \%)$ & 5.15 & $5(10 \%)$ & $2(4 \%)$ & 4.082 & $3(6 \%)$ & $1(2 \%)$ \\
\hline $\mathrm{T}$ & 4.693 & $1(2 \%)$ & $1(2 \%)$ & 5.069 & $2(4 \%)$ & 0 & 4.86 & $3(6 \%)$ & $2(4 \%)$ & 3.973 & $4(8 \%)$ & $2(4 \%)$ \\
\hline T-MMC & 6.619 & $11(22 \%)$ & $3(6 \%)$ & 6.529 & $8(16 \%)$ & $5(10 \%)$ & 6.614 & $12(24 \%)$ & $6(12 \%)$ & 4.216 & $4(8 \%)$ & $4(8 \%)$ \\
\hline
\end{tabular}

See Materials and methods for a detailed description of this experiment.

Time - incubation time (h) after MMC was washed out.

Strain references are as follows: dDCO, $\Delta$ ligD $\Delta k u$; mc2, Mycobacterium smegmatis wild type; RecA, Mycobacterium smegmatis $\Delta$ recA; T, Mycobacterium smegmatis $\Delta$ lig $D \Delta k u \Delta r e c A$.

$M M C$ - cells were incubated in $25 \mathrm{ng} \mathrm{mL}^{-1} \mathrm{MMC}$ before changing to fresh media.

At least 50 cells were measured at each time point.

\section{Influence of recA-dependent processes and NHEJ on cell division after treatment with MMC}

Bacterial cells exposed to MMC have inhibition of replication and cell division (Kawai et al., 2003). It is generally accepted that cells that cannot divide continue to grow and elongate (Dziadek et al., 2002, 2003). Upon repair of DNA damage, cells should return to the normal cell cycle, with a consequent decrease in cell length upon completion of cell division. To assess if the effects of MMC on the mycobacterial cell cycle were influenced by RecA- or NHEJ-dependent processes, the morphology of cells was monitored after DNA damage with MMC. The M. smegmatis wild-type strain and all mutated strains generated during this study were grown in media with and without MMC, as described above. The DNA damage caused by MMC will block DNA replication, which will inhibit cell division. To determine the extent of inhibition of cell division, cell length was measured immediately after treatment with MMC and 12, 24 and $45 \mathrm{~h}$ later (Table 3). Immediately after treatment with MMC, all mutant strains had a larger average size than the wild type, but this was particularly pronounced for the double mutant $(\Delta l i g D-\Delta k u)$ and triple mutant $(\Delta l i g D-\Delta k u-\Delta r e c A)$. Interestingly, for $\Delta r e c A$ strains there was a delay in the return of cell length to that before MMC treatment, suggesting that intact RecA is required for the optimal response of mycobacterial cells to DNA damage from MMC. At longer times of growth, all mutant strains were more sensitive to MMC than the wild type, as indicated by the presence of more elongated cells. Moreover, mutants with defective NHEJand RecA-dependent pathways were the most sensitive.
Thus, there is qualitative agreement between this data and that observed in the growth experiments, displaying the major role of RecA-dependent pathways in repairing DNA damaged with MMC, although a minor role of the NHEJ pathway is also detectable.

\section{Discussion}

Previous studies have identified that functional NHEJ proteins are encoded by the genomes of some mycobacteria, including Mycobacterium smegmatis (Weller et al., 2002; Della et al., 2004; Gong et al., 2004, 2005). To assess the roles of NHEJ in bacterial DNA repair, especially in its relationship with RecA-dependent processes, we constructed M. smegmatis strains that were defective in the production of proteins central to NHEJ (LigD and/or Ku), RecAdependent processes and both systems. As it was possible to obtain strains with deletions in all three of the relevant chromosomal genes ( $\Delta l i g D-\Delta k u-\Delta r e c A)$, NHEJ- and RecAdependent processes are not essential when $M$. smegmatis grows in rich media. This is consistent with previous findings with Bacillus subtilis (Weller et al., 2002). Use of several different assays of DNA repair capacity identified that both NHEJ and RecA-dependent processes could bring about repair of the damage, but found little evidence for synergistic interactions between these two processes. For example, the repair of DNA damaged with MMC or cis-DDP was coordinated mainly by RecA-dependent processes, with NHEJ playing a relatively minor role. Conversely, in an assay that is typically used to assess NHEJ capability, the efficiency 
of transformation of M. smegmatis by linearized plasmids was dramatically reduced in the absence of functional NHEJ proteins, whereas inactivation of $\operatorname{rec} A$ had no significant effect.

To evaluate the relationship of RecA-dependent pathways and NHEJ in bacterial DNA repair systems, we used the DNA-damaging agent MMC. This antitumour compound forms adducts in DNA including ICLs that are extremely toxic (Dronkert \& Kanaar, 2001). These adducts inhibit separation of DNA strands, blocking transcription or replication of DNA. Although the mechanism of repair of such damage is not completely clear, stalled replication forks can result in fork regression and formation of DSBs within DNA (De Silva et al., 2000; McHugh et al., 2000; Dronkert \& Kanaar, 2001; Niedernhofer et al., 2004). In Escherichia coli and Saccharomyces cerevisiae, efficient repair of ICLs requires intact NER and HR systems, for which RecA activity is important (Cole \& Sinden, 1975; Jachymczyk et al., 1981). Using the various mutants constructed here, it is clear that RecA-dependent processes are the primary mechanism in mycobacteria to repair DNA damaged with MMC. The $M$. smegmatis $\Delta$ recA strain viability was decreased by $99.9 \%$ in $4 \mathrm{~h}$ with $25 \mathrm{ng} \mathrm{mL}^{-1}$ of MMC, and twice this concentration was found to be lethal for these cells. Upon exposure to $25 \mathrm{ng} \mathrm{mL}^{-1}$ of MMC the wild-type strain and NHEJ defective mutants viability decreased by only $50 \%$, although monitoring of the number of viable cells in these strains revealed a slow-down in the doubling time of NHEJdefective mutants (Fig. 2b). As this effect was observed in the three different strains mutated for NHEJ, repeated in three to five independent experiments, it suggests a minor but detectable role of mycobacterial NHEJ in the repair of DNA damaged by MMC. These observations were confirmed by the analysis of the morphology of the cells. The bacterial cells defective in division became elongated, in a manner similar to that described for FtsA-Z conditional mutants (for reviews, see Margolin, 2000; Errington, 2003). MMC treatment damages DNA, affects replication, eventually leading to inhibition of cell division. Thus, cells with extensive DNA damage should be longer than dividing, undamaged cells. Compared with wild-type strains, the NHEJ-defective strains contained more elongated cells for up to $12 \mathrm{~h}$ after treatment with MMC, confirming that these strains are not as effective as the wild-type strain in their repair of damage induced by MMC. It is interesting that elongation of $\Delta \mathrm{rec}$ A cells treated with MMC were observed for longer periods than compared with wild-type strains or those defective only in NHEJ. This indicates that intact RecA protein is important for mycobacteria to recover from DNA damage induced by MMC, consistent with a central role of intact RecA for returning cells to their normal cell cycle after DNA damage (Lusetti \& Cox, 2002). The natural mutation rate of stationary phase is higher compared with the logarithmic phase of growth because of accumulation of natural metabolites, which can be mutagenic to DNA. We observed that a small population of cells defective in both RecA and NHEJ were elongated in stationary phase $\left(\mathrm{OD}_{600 \mathrm{~nm}}=2.5\right)$ even without previous contact with MMC. Such cells were not observed in stationary cultures of wildtype strain or mutants defective in only RecA or NHEJ. Thus, the absence of both RecA and NHEJ leads to increased problems in relation to the repair of spontaneous damage, although the reasons behind this are unclear and the comprehension of the specific role of NHEJ warrants further investigation.

\section{Acknowledgements}

We thank Laura Bowater and Heather Sayer for comments on this manuscript. We acknowledge financial support from the State Committee for Scientific Research (KBN, contract no. 3P04C06825) and travel grants awarded by the British Council and BBSRC ISIS. We thank Dr T. Parish for the pJam2 expression vector and p2NIL/pGOAL17 recombination system.

\section{References}

Aravind L \& Koonin EV (2001) Prokaryotic homologs of the eukaryotic DNA-end-binding protein $\mathrm{ku}$, novel domains in the ku protein and prediction of a prokaryotic double-strand break repair system. Genome Res 11: 1365-1374.

Bowater RP \& Doherty AJ (2005) Making ends meet: repairing breaks in bacterial DNA by non-homologous end-joining. PLoS Genet, 2: 93-99.

Cole RS \& Sinden RR (1975) Repair of cross-linked DNA in Escherichia coli. Basic Life Sci 5B: 487-495.

Davis EO, Springer B, Gopaul KK, Papavinasasundaram KG, Sander P \& Bottger EC (2002) DNA damage induction of recA in Mycobacterium tuberculosis independently of RecA and LexA. Mol Microbiol 46: 791-800.

Della M, Palmbos PL, Tseng HM, Tonkin LM, Daley JM, Topper LM, Pitcher RS, Tomkinson AE, Wilson TE \& Doherty AJ (2004) Mycobacterial Ku and ligase proteins constitute a twocomponent NHEJ repair machine. Science 306: 683-685.

Doherty AJ, Jackson SP \& Weller GR (2001) Identification of bacterial homologues of the Ku DNA repair proteins. FEBS Lett 500: 186-188.

Dronkert ML \& Kanaar R (2001) Repair of DNA interstrand cross-links. Mutat Res 486: 217-247.

Dziadek J, Madiraju MV, Rutherford SA, Atkinson MA \& Rajagopalan M (2002) Physiological consequences associated with overproduction of Mycobacterium tuberculosis FtsZ in mycobacterial hosts. Microbiology 148: 961-971.

Dziadek J, Rutherford SA, Madiraju MV, Atkinson MA \& Rajagopalan M (2003) Conditional expression of 
Mycobacterium smegmatis $\mathrm{ftsZ}$, an essential cell division gene. Microbiology 149: 1593-1603.

Errington J (2003) Dynamic proteins and a cytoskeleton in bacteria. Nat Cell Biol 5: 175-178.

Frischkorn K, Sander P, Scholz M, Teschner K, Prammananan T \& Bottger EC (1998) Investigation of mycobacterial recA function: protein introns in the RecA of pathogenic mycobacteria do not affect competency for homologous recombination. Mol Microbiol 29: 1203-1214.

Gong C, Martins A, Bongiorno P, Glickman M \& Shuman S (2004) Biochemical and genetic analysis of the four DNA ligases of mycobacteria. J Biol Chem 279: 20594-20606.

Gong C, Bongiorno P, Martins A, Stephanou NC, Zhu H, Shuman S \& Glickman MS (2005) Mechanism of nonhomologous end-joining in mycobacteria: a low-fidelity repair system driven by Ku, ligase D and ligase C. Nat Struct Mol Biol 12: 304-312.

Hefferin ML \& Tomkinson AE (2005) Mechanism of DNA double-strand break repair by non-homologous end joining. DNA Repair 4: 639-648.

Jachymczyk WJ, von Borstel RC, Mowat MR \& Hastings PJ (1981) Repair of interstrand cross-links in DNA of Saccharomyces cerevisiae requires two systems for DNA repair: the RAD3 system and the RAD51 system. Mol Gen Genet 182: 196-205.

Jackson SP (2002) Sensing and repairing DNA double-strand breaks. Carcinogenesis 23: 687-696.

Kawai Y, Moriya S \& Ogasawara N (2003) Identification of a protein, YneA, responsible for cell division suppression during the SOS response in Bacillus subtilis. Mol Microbiol 47: 1113-1122.

Khil PP \& Camerini-Otero RD (2002) Over 1000 genes are involved in the DNA damage response of Escherichia coli. Mol Microbiol 44: 89-105.

Lieber MR, Ma Y, Pannicke U \& Schwarz K (2003) Mechanism and regulation of human non-homologous DNA end-joining. Nat Rev Mol Cell Biol 4: 712-720.

Lusetti SL \& Cox MM (2002) The bacterial RecA protein and the recombinational DNA repair of stalled replication forks. Annu Rev Biochem 71: 71-100.

Madiraju MV, Qin MH \& Rajagopalan M (2000) Development of simple and efficient protocol for isolation of plasmids from mycobacteria using zirconia beads. Lett Appl Microbiol 30: 38-41.

Margolin W (2000) Themes and variations in prokaryotic cell division. FEMS Microbiol Rev 24: 531-548.

McHugh PJ, Sones WR \& Hartley JA (2000) Repair of intermediate structures produced at DNA interstrand crosslinks in Saccharomyces cerevisiae. Mol Cell Biol 20: 3425-3433.

Niedernhofer LJ, Odijk H, Budzowska M, et al. (2004) The structure-specific endonuclease Ercc1-Xpf is required to resolve DNA interstrand cross-link-induced double-strand breaks. Mol Cell Biol 24: 5776-5787.

Papavinasasundaram KG, Anderson C, Brooks PC, Thomas NA, Movahedzadeh F, Jenner PJ, Colston MJ \& Davis EO (2001) Slow induction of RecA by DNA damage in Mycobacterium tuberculosis. Microbiology 147: 3271-3279.

Parish T \& Stoker NG (2000) Use of a flexible cassette method to generate a double unmarked Mycobacterium tuberculosis tlyA plcABC mutant by gene replacement. Microbiology 146: 1969-1975.

Rand L, Hinds J, Springer B, Sander P, Buxton RS \& Davis EO (2003) The majority of inducible DNA repair genes in Mycobacterium tuberculosis are induced independently of RecA. Mol Microbiol 50: 1031-1042.

Sambrook J \& Russell D (2001) Molecular Cloning: A Laboratory Manual. Cold Spring Harbor Laboratory Press, Cold Spring Harbor, NY.

De Silva IU, McHugh PJ, Clingen PH \& Hartley JA (2000) Defining the roles of nucleotide excision repair and recombination in the repair of DNA interstrand cross-links in mammalian cells. Mol Cell Biol 20: 7980-7990.

Snapper SB, Melton RE, Mustafa S, Kieser T \& Jacobs WR Jr (1990) Isolation and characterization of efficient plasmid transformation mutants of Mycobacterium smegmatis. Mol Microbiol 4: 1911-1919.

Triccas JA, Parish T, Britton WJ \& Grequel B (1998) An inducible expression system permitting the efficient purification of a recombinant antigen from Mycobacterium smegmatis. FEMS Microbiol Lett 167: 151-156.

Weller GR \& Doherty AJ (2001) A family of DNA repair ligases in bacteria? FEBS Lett 505: 340-342.

Weller GR, Kysela B, Roy R, et al. (2002) Identification of a DNA non-homologous end-joining complex in bacteria. Science 297: 1686-1689. 